\title{
Dimensions of sleepiness and their correlations with sleep-disordered breathing in mild sleep apnea*,**
}

\author{
Dimensões da sonolência e suas correlações com os transtornos \\ respiratórios do sono na apneia do sono leve
}

\author{
Denis Martinez, Magali Santos Lumertz, Maria do Carmo Sfreddo Lenz
}

\begin{abstract}
Objective: There are many ways of assessing sleepiness, which has many dimensions. In patients presenting a borderline apnea-hypopnea index ( $\mathrm{AHl}$, expressed as events/hour of sleep), the mechanisms of excessive daytime sleepiness (EDS) remain only partially understood. In the initial stages of sleep-disordered breathing, the AHI might be related to as-yet-unexplored EDS dimensions. Methods: We reviewed the polysomnography results of 331 patients (52\% males). The mean age was $40 \pm 13$ years, and the mean AHI was $4 \pm 2$ (range, $0-9$ ). We assessed ten potential dimensions of sleepiness based on polysomnography results and medical histories. Results: The AHI in non-rapid eye movement (NREM) stage 1 sleep (AHI-N1), in NREM stage 2 sleep (AHI-N2), and in REM sleep (AHI-REM) were, respectively, $6 \pm 7,3 \pm 3$ and $10 \pm 4$. The AHI-N2 correlated significantly with the greatest number of EDS dimensions (5/10), including the Epworth sleepiness scale score $(r=0.216, p<0.001)$. Factor analysis, using Cronbach's alpha, reduced the variables to three relevant factors: QUESTIONNAIRE $(\alpha=0.7)$; POLYSOMNOGRAPHY $(\alpha=0.68)$; and COMPLAINTS $(\alpha=0.55)$. We used these factors as dependent variables in a stepwise multiple regression analysis, adjusting for age, gender, and body mass index. The AHI-N1 correlated significantly with POLYSOMNOGRAPHY ( $\beta=-0.173, p=0.003)$, and the AHI-N2 correlated significantly with COMPLAINTS $(\beta=-0.152, p=0.017)$. The AHI-REM did not correlate with any factor. Conclusions: Our results underscore the multidimensionality of EDS in mild sleep apnea.
\end{abstract}

Keywords: Disorders of excessive somnolence; Sleep apnea syndromes; Sleep, REM; Polysomnography.

\section{Resumo}

Objetivo: Há muitas formas de avaliação da sonolência, a qual possui diversas dimensões. Em pacientes com um indice de apneia-hipopneia (IAH, expresso em eventos/hora de sono) limitrofe, os mecanismos da sonolência excessiva diurna (SED) permanecem apenas parcialmente esclarecidos. Nos estágios iniciais do transtorno respiratório do sono, o IAH pode estar relacionado a outras dimensões da SED ainda não exploradas. Métodos: Revisamos os resultados de polissonografia de 331 pacientes (52\% do sexo masculino). A idade média foi de $40 \pm 13$ anos e o IAH médio de $4 \pm 2$ (variação, 0-9). Avaliamos dez dimensões potenciais de sonolência com base nos resultados da polissonografia e da história médica. Resultados: 0 IAH em sono non-rapid eye movement (NREM) estágio 1 (IAH-N1), em sono NREM estágio 2 (IAH-N2), e em sono REM (IAH-REM) foram, respectivamente, $6 \pm 7,3 \pm 3$ e $10 \pm 4$. O IAH-N2 se correlacionou significantemente com o maior número de dimensões de SED (5/10), incluindo o escore da escala de sonolência de Epworth $(r=0,216, p<0,001)$. Análise de fatores, utilizando-se o alfa de Cronbach, reduziu as variáveis a três fatores relevantes: QUESTIONÁRIO $(\alpha=0,7)$; POLISSONOGRAFIA $(\alpha=0,68)$; e QUEIXAS $(\alpha=0,55)$. Usando esses fatores como variáveis dependentes na regressão múltipla, ajustando para idade, gênero e índice de massa corporal, o IAH-N1 se correlacionou significantemente com POLISSONOGRAFIA $(\beta=-0,173, p=0,003)$ e o IAH-N2, com QUEIXAS $(\beta=-0,152, p=0,017)$. 0 IAH-REM não se correlacionou com nenhum fator. Conclusões: Nossos resultados confirmam a multidimensionalidade da SED na apneia do sono leve.

Descritores: Distúrbios do sono por sonolência excessiva; Síndromes da apneia do sono; Sono REM; Polissonografia.

\footnotetext{
* Study carried out in the Division of Cardiology of the Porto Alegre Hospital de Clínicas, Universidade Federal do Rio Grande do Sul UFRGS, Federal University of Rio Grande do Sul - Porto Alegre, Brazil.

Correspondence to: Denis Martinez. Serviço de Cardiologia, Hospital de Clinicas de Porto Alegre, Rua Ramiro Barcelos, 2350, CEP 90035-903, Porto Alegre, RS, Brasil.

Tel 5551 3022-2282. E-mail: dm@ufrgs.br

Financial support: This study received financial support from the Fundo de Incentivo à Pesquisa e Eventos do Hospital de Clínicas de Porto Alegre (FIPE-HCPA, Porto Alegre Hospital de Clínicas Events and Research Incentive Fund).

Submitted: 5 August 2008. Accepted, after review: 29 December 2008.

**A versão completa em português deste artigo está disponivel em www.jornaldepneumologia.com.br
} 


\section{Introduction}

Obstructive sleep apnea-hypopnea syndrome (OSAHS) is a life-threatening disease that causes various symptoms, ${ }^{(1,2)}$ the most serious of which is sleepiness due to the increased risk for motor-vehicle accidents. ${ }^{(3-5)}$ The pathophysiology of OSAHS is complex. ${ }^{(6)}$ One of the major mechanisms of OSAHS is that of respiratory arousals, which fragment sleep, resulting in excessive daytime sleepiness (EDS). In populations with OSAHS, however, polysomnographic indices of sleep fragmentation seldom exhibit a strong association with objectively or subjectively measured EDS. ${ }^{(7)}$ The gold standard for assessing sleepiness is the multiple sleep latency test (MSLT), and one of the most useful parameters in evaluating patients suspected of suffering from sleep-disordered breathing (SDB) is the apnea-hypopnea index (AHI), which is expressed as events/hour of sleep. Using the MSLT, Kass et al. found that an AHI during rapid eye movement (REM) sleep (AHI-REM) $>15$ is associated with EDS, even in individuals with an overall $\mathrm{AHI}<10{ }^{(8)}$ This finding suggests that fragmentation of REM sleep is more important than is overall sleep fragmentation as a source of EDS. ${ }^{(8)}$ Although subsequent studies have not confirmed this finding, ${ }^{(9,10)}$ the discrepancies could be due to methodological differences related to the use of the MSLT. ${ }^{(11)}$ Upper airway resistance syndrome (UARS), another cause of EDS, ${ }^{(12)}$ is also characterized by respiratory arousals, without, however, oxygen desaturation or cessation of breathing. Hypoxemia is associated with hypersomnia in OSAHS. ${ }^{(13)}$ However, in individuals with UARS, oxygen desaturation is negligible or absent. Therefore, the sources of EDS in patients with mild OSAHS and UARS remain only partially understood.

In the Sleep Heart Health Study, ${ }^{(14)}$ involving 1,824 individuals, the $\mathrm{AHI}$ was found to be significantly associated with EDS, as measured by the Epworth sleepiness scale (ESS), a subjective, self-report measure. ${ }^{(15)}$ Therefore, subjective as well as objective measures of sleepiness can be used in order to identify correlations with indices of respiratory sleep disturbance. Subjective methods of assessing EDS (typically questionnaires) present certain limitations, as do objective methods (typically measurements of sleep latency), and there is an ongoing debate as to which method best reflects the severity of
OSAHS. It has been suggested that sleepiness has multiple dimensions, which are assessed by different tests, and that there is no gold standard for measuring sleepiness. ${ }^{(16)}$ One recent study identified three dimensions of sleepiness: perceived daytime sleepiness; subjective sleep propensity in active situations; and subjective sleep propensity in passive situations. ${ }^{(17)}$

The word "sleepiness" has a variety of meanings and interpretations; individuals with OSAHS more often use terms such as "fatigue", "tiredness" and "lack of energy". Defining sleepiness has implications for the differential diagnosis. There are four possible diagnoses for a patient suspected of having OSAHS ${ }^{(18)}$ :

- OSAHS, if the AHI is > 5 and the patient reports EDS

- UARS, if the AHI is $<5$ and the patient reports EDS

- SDB, if the $\mathrm{AHI}$ is > 5 and there is no evidence of sleepiness

- normal, if the AHl is $<5$ and there is no evidence of sleepiness

Clinicians face a diagnostic challenge when subjective EDS is difficult to establish. For instance, if the patient complains only of tiredness in the morning or the ESS score is $<10$. The diagnosis can also be complex when borderline polysomnography values are obtained. Examples of such borderline values include an $\mathrm{AHI} \approx 5$ or a mean sleep latency (as determined by the MSLT) $\approx 10 \mathrm{~min}$.

Kass et al. brought the important clinical problem of borderline SDB to light and initiated the search for different causes of EDS in patients with SDB. ${ }^{(8)}$ Although the results obtained by those authors are in contrast with all subsequent evidence, we can assume that the AHI-REM conveys some type of diagnostic information that was revealed only in their study. Most authors acknowledge the urgent need for evidenced-based data to help define which symptoms influence the diagnostic process, as well as to identify the precise normal limits of polysomnography values. To date, the decisions made by international societies regarding the diagnostic criteria of OSAHS have been largely based on experience rather than on evidence. ${ }^{(19)}$ Because sleepiness seems to be a multidimensional symptom, we decided to test the hypothesis that readily available polysomnography data and medical history can explain 
Table 1 - Anthropometric, clinical, and polysomnographic variables by gender.

\begin{tabular}{|c|c|c|c|c|}
\hline Variable & Total & Males & Females & $p$ \\
\hline & $(n=331)$ & $(n=171)$ & $(n=160)$ & \\
\hline Age, years & $40 \pm 12.7$ & $39.1 \pm 12.2$ & $40.9 \pm 13.2$ & 0.20 \\
\hline Body mass index, $\mathrm{kg} / \mathrm{m}^{2}$ & $24.8 \pm 3.7$ & $25.9 \pm 3$ & $23.7 \pm 3.9$ & 0.000 \\
\hline Neck circumference, $\mathrm{cm}$ & $36.34 \pm 4.43$ & $39 \pm 3$ & $33.4 \pm 4.1$ & 0.000 \\
\hline Waist, cm & $85.19 \pm 11.6$ & $90.68 \pm 9.1$ & $79.19 \pm 11.06$ & 0.000 \\
\hline Epworth Sleepiness Scale & $8.86 \pm 4.8$ & $9.91 \pm 5$ & $8 \pm 4$ & 0.000 \\
\hline Insomnia as the chief complaint, $\%$ & 43.87 & 37.34 & 50.65 & 0.008 \\
\hline Sleepiness as the chief complaint, $\%$ & 16.45 & 15.18 & 17.76 & 0.47 \\
\hline Snoring as the chief complaint, \% & 20 & 24.68 & 15.13 & 0.02 \\
\hline Smoking, \% & 10.87 & 8.77 & 13.12 & 0.20 \\
\hline Diabetes, \% & 0.9 & 0.58 & 1.25 & 0.95 \\
\hline Depression, \% & 6.85 & 4.73 & 9.21 & 0.07 \\
\hline Latency to stage $2, \min$ & $28.9 \pm 26.8$ & $25 \pm 22.7$ & $33.1 \pm 30.1$ & 0.006 \\
\hline Latency to REM sleep, min & $101 \pm 56.4$ & $97.6 \pm 47.9$ & $104.6 \pm 64.2$ & 0.25 \\
\hline Sleep efficiency, \% & $80.8 \pm 12.4$ & $82.7 \pm 12.2$ & $78.8 \pm 12.3$ & 0.004 \\
\hline Wakefulness after sleep onset, \% & $11.6 \pm 9.5$ & $10.4 \pm 9.2$ & $12.9 \pm 9.8$ & 0.02 \\
\hline Stage 1 sleep, \% & $8.3 \pm 3$ & $8.4 \pm 3$ & $8.1 \pm 2.9$ & 0.37 \\
\hline Stage 2 sleep, \% & $47.4 \pm 9.3$ & $47.9 \pm 8.6$ & $46.8 \pm 10$ & 0.28 \\
\hline Slow wave sleep, \% & $16.1 \pm 6.6$ & $16.6 \pm 6.1$ & $15.7 \pm 7.1$ & 0.19 \\
\hline REM sleep, \% & $16.6 \pm 5.2$ & $16.7 \pm 4.9$ & $16.5 \pm 5.5$ & 0.79 \\
\hline AHI-TST, events/hour of sleep & $4.15 \pm 2.4$ & $4.7 \pm 2.3$ & $3.5 \pm 2.4$ & 0.000 \\
\hline AHI-N1, events/hour of sleep & $6.2 \pm 7.1$ & $7.7 \pm 7.8$ & $4.6 \pm 5.9$ & 0.000 \\
\hline AHI-N2, events/hour of sleep & $3.2 \pm 2.9$ & $4.2 \pm 3.2$ & $2.2 \pm 2.1$ & 0.000 \\
\hline AHI-REM, events/hour of sleep & $9.7 \pm 7.4$ & $9.4 \pm 6.7$ & $10 \pm 8$ & 0.51 \\
\hline $\mathrm{SaO}_{2} \min , \%$ & $89.2 \pm 4.2$ & $88.5 \pm 3.9$ & $89.9 \pm 4.5$ & 0.004 \\
\hline
\end{tabular}

REM: rapid eye movement; AHI-TST: apnea-hyponea index during total sleep time; AHI-N1: apnea-hyponea index during stage 1 sleep; AHI-N2: apnea-hyponea index during stage 2 sleep; AHI-REM: apnea-hyponea index during REM sleep; and $\mathrm{SaO}_{2}$ min: minimum arterial oxygen saturation.

the evolution of sleepiness in the initial phases of SDB, during which the REM-sleep specific AHI might be associated with other, as yet unexplored, dimensions of EDS.

\section{Methods}

In this retrospective observational study, we stored selected patient and polysomnography data in computer files. The sample size was defined on the basis of data in the literature. ${ }^{(9)}$ From January of 2000 to June of 2005 , 3,973 patients ( $\geq 18$ years of age), suspected of having sleep disorders, underwent clinical evaluation-including determination of body mass index (BMI)-and overnight polysomnography at the sleep laboratory of the Federal University of Rio Grande do Sul School of Medicine, in Porto Alegre, Brazil. After the desired sample size had been attained, we reviewed the database. We found the overall $\mathrm{AHI}$ to be $<10$ in
1,456 patients. Among those patients, the clinical data were complete for 378 , who were therefore eligible for inclusion in the study. We excluded 26 individuals who had not spent at least $30 \mathrm{~min}$ in REM sleep and in non-REM (NREM) sleep, as well as 21 individuals who had been taking anxiolytic, antidepressant or psychotropic substances. As can be seen in Table 1, the 331 cases selected presented the following characteristics: suspected OSAHS; $\mathrm{AHI}<10$; overnight polysomnography; and complete self-report data regarding sleepiness. The study was approved by the Human Research Ethics Committee of the Porto Alegre Hospital de Clínicas.

Polysomnography data were recorded from 11:00 pm to 7:00 am, as described elsewhere, ${ }^{(20)}$ and scored according to criteria adopted by the Brazilian Sleep Association. ${ }^{(21)}$ Respiratory parameters were assessed by calibrated inductance 
Table 2 - Nonparametric Spearman's correlation coefficients of sleepiness dimensions with stage-specific apnea-hypopnea indices.

\begin{tabular}{lccccc}
\hline \multicolumn{1}{c}{ Dimension } & AHl-N1 & AHl-N2 & AHI-REM & AHl-TST & ESS \\
\hline Epworth sleepiness scale & $0.125^{*}$ & $0.197^{* * *}$ & -0.026 & $0.131^{*}$ & $-0.289^{* * *}$ \\
Latency to stage 2 & $-0.236^{* * *}$ & $-0.154^{* * *}$ & 0.038 & $-0.120^{*}$ & $0.325^{* *}$ \\
Sleep efficiency & $0.308^{* * *}$ & $0.259^{* * *}$ & 0.035 & $0.193^{* *}$ & 0.146 \\
Years of sleepiness & -0.020 & -0.036 & 0.088 & 0.043 & $0.364^{* *}$ \\
Sleepiness as the chief complaint (yes/no) & 0.035 & 0.012 & 0.034 & 0.015 & -0.016 \\
Presence of comorbidities (yes/no) & 0.010 & 0.036 & 0.036 & 0.026 & 0.132 \\
Timing of sleepiness (morning/afternoon) & 0.068 & 0.129 & 0.144 & $0.222^{* *}$ & $0.342^{* *}$ \\
Sleepiness while driving (yes/no) & 0.059 & 0.082 & -0.011 & 0.058 & $0.483^{* *}$ \\
Sleepiness while working (yes/no) & 0.074 & 0.018 & 0.002 & 0.078 & $-0.344^{* *}$ \\
lnsomnia as the chief complaint (yes/no) & $-0.202^{* * *}$ & $-0.302^{* * *}$ & -0.018 & $-0.216^{* *}$ & -0.34 \\
\hline AHt-NI: ar
\end{tabular}

AHI-N1: apnea-hypopnea index during stage 1 sleep; AHI-N2: apnea-hypopnea index during stage 2 sleep; AHI-REM: apnea-hypopnea index during rapid eye movement sleep; AHI-TST: apnea-hypopnea index during total sleep time; and ESS: Epworth sleepiness scale. * Level of significance set at 0.05 ; and ${ }^{* *}$ Level of significance set at 0.01 .

plethysmography (Respitrace; AMI, Ardsley, NY, USA) or by Respitrace plus a nasal cannula/pressure transducer system (EMSA; Rio de Janeiro, Brazil). Arousals were scored according to the criteria established by the American Academy of Sleep Medicine. ${ }^{(22)}$ The AHI was calculated separately for total sleep time (AHI-TST), REM sleep (AHI-REM), stage 1 NREM sleep (AHI-N1) and stage 2 NREM sleep (AHI-N2).

A translated (Brazilian Portuguese) version of the ESS was employed. The scale was reviewed

Table 3 - Structure matrix of factor analysis for seven dimensions of sleepiness. ${ }^{a}$

\begin{tabular}{|c|c|c|c|}
\hline \multirow[t]{2}{*}{ Factor } & \multicolumn{3}{|c|}{ Component } \\
\hline & 1 & 2 & 3 \\
\hline \multicolumn{4}{|l|}{ 1. QUESTIONNAIRE } \\
\hline Sleepiness at work & 0.830 & & \\
\hline Sleepiness while driving & 0.802 & & \\
\hline $\begin{array}{l}\text { Epworth sleepiness } \\
\text { scale score }\end{array}$ & 0.701 & & \\
\hline \multicolumn{4}{|l|}{ 2. POLYSOMNOGRAPHY } \\
\hline Sleep efficiency & \multicolumn{3}{|c|}{0.869} \\
\hline Sleep urgency & \multicolumn{3}{|c|}{0.846} \\
\hline \multicolumn{4}{|l|}{ 3. COMPLAINTS } \\
\hline No insomnia & & & -0.823 \\
\hline $\begin{array}{l}\text { Sleepiness as chief } \\
\text { complaint }\end{array}$ & & & -0.787 \\
\hline \multirow[t]{2}{*}{ Cronbach's alpha } & 0.7 & 0.68 & 0.55 \\
\hline & \multicolumn{3}{|c|}{ Factor correlations } \\
\hline \multicolumn{4}{|l|}{ 1. QUESTIONNAIRE } \\
\hline 2. POLYSOMNOGRAPHY & 0.194 & & \\
\hline 3. COMPLAINTS & -0.222 & -0.223 & \\
\hline
\end{tabular}

${ }^{a}$ Extraction method: principal component analysis; rotation method: oblimin with Kaiser normalization. by a technician, who assisted patients in understanding the questions.

To assess EDS, we utilized ten variables that represented different putative dimensions of sleepiness. Four were parametric variables, and six were binary variables:

Parametric variables -

- ESS score

- latency to stage $2^{(23)}$

- sleep efficiency

- years since EDS onset

Binary variables -

- sleepiness as the chief complaint

- at least one comorbidity, such as depression, ${ }^{(24-26)}$ diabetes, ${ }^{(24)}$ or current smoking $^{(25)}$

- morning/afternoon sleepiness, as defined based on the answer to the question "At what time of day do you feel sleepiest?" (if the subject indicated any morning hour plus any afternoon hour, we classified this as morning/afternoon sleepiness)

- report of having fallen asleep after driving for $1 \mathrm{~h}$ or less

- report of having fallen asleep after working seated for $1 \mathrm{~h}$ or less

- insomnia as the chief complaint. ${ }^{(27)}$

Patients were classified as suffering from depression if meeting at least four of the criteria set forth in the Diagnostic and Statistical Manual of Mental Disorders, Fourth edition, or having been previously diagnosed or treated for depression. An ESS score > 10 was considered indicative of EDS. ${ }^{(28)}$ 
Data are shown as means and standard deviation. The statistical analysis was performed using the program Statistical Package for the Social Sciences, version 13.0 (SPSS Inc., Chicago, IL, USA). Due to their non-normal distribution, all data related to stage-specific AHls and sleep efficiency were analyzed using Spearman's nonparametric correlation test. For linear and logistic regressions, we utilized the square roots of the AHls. Sleep efficiency also presented nonnormal distribution and were therefore converted to a natural logarithm. A receiver operating characteristic curve analysis was used in order to identify an $\mathrm{AHI}$ cut-off point that would predict an ESS score $>10$.

Chi-square test was used to compare non-parametric variables. To identify interrelationships among the ten putative sleepiness variables, we employed reliability analysis. Because "sleep latency" and "insomnia as the chief complaint" were negatively correlated with sleepiness, we created the inverse variables "sleep urgency" (1/sleep latency) and "no insomnia".

To reduce the number of dimensions and to determine which dimensions assessed the same factor, we conducted a factor analysis using principal component analysis as the extraction method and an oblique method of rotation. The Kaiser-Meyer-Olkin measure was used in order to assess sampling adequacy.

\section{Results}

In the present study, the mean BMI was higher among men than among women $\left(25.9 \pm 3 \mathrm{~kg} / \mathrm{m}^{2}\right.$ vs. $\left.23.7 \pm 3.9 \mathrm{~kg} / \mathrm{m}^{2}\right)$. Men also more often reported snoring (25\% vs. 15\%) and were sleepier (ESS score $=10 \pm 5$ vs. $8 \pm 4$; $p<0.001)$. There were 113 patients $(34 \%)$ with an ESS score $>10$. An AHI-REM > 15 did not present a significant association with ESS score $>10\left(\chi^{2}=0.61 ; p=0.49\right)$.

The bivariate correlations of sleepiness dimensions with stage-specific AHls and with ESS score are displayed in Table 2. The AHI-TST correlated significantly with four of the putative dimensions of sleepiness, whereas the AHI-N1 correlated significantly with three, the AHI-N2 correlated significantly with five, and the AHI-REM correlated significantly only with morning/afternoon sleepiness. The ESS score correlated significantly with six of the nine possible dimensions of sleepiness.

The receiver operating characteristic curve analysis of all AHls for detecting an ESS score $>10$ was significant only for the AHI-N2 (area under the curve $=0.6, p=0.006$ ), the best accuracy being obtained when the AHI-N2 cut-off value was 2.5 (sensitivity $=54 \%$; specificity $=57 \%$ ).

In the reliability analysis, three of the putative sleepiness dimensions (years since EDS onset; comorbidities; and morning/afternoon

Table 4 - Multiple linear regression model for sleepiness factors. ${ }^{a}$

\begin{tabular}{|c|c|c|c|c|c|c|c|c|c|}
\hline \multirow[t]{2}{*}{ Component } & \multicolumn{3}{|c|}{ Questionnaire } & \multicolumn{3}{|c|}{ Polysomnography } & \multicolumn{3}{|c|}{ Complaints } \\
\hline & $\mathrm{B} \pm \mathrm{SEM}$ & $\beta$ & Sign & $\mathrm{B} \pm$ SEM & $\beta$ & Sign & $\mathrm{B} \pm \mathrm{SEM}$ & $\beta$ & Sign \\
\hline $\begin{array}{l}\text { AHI-N } 1 \text {, } \\
1 \text { event/hour of sleep }\end{array}$ & $\begin{array}{c}-0.004 \pm \\
0.008\end{array}$ & -0.037 & 0.559 & $\begin{array}{c}-0.022 \pm \\
0.007\end{array}$ & -0.173 & 0.003 & $\begin{array}{l}-0.001 \pm \\
0.007\end{array}$ & -0.011 & 0.852 \\
\hline $\begin{array}{l}\text { AHI-N2, } \\
1 \text { event/hour of sleep }\end{array}$ & $\begin{array}{c}0.016 \pm \\
0.020\end{array}$ & 0.054 & 0.429 & $\begin{array}{c}-0.029 \pm \\
0.019\end{array}$ & -0.093 & 0.129 & $\begin{array}{l}-0.042 \pm \\
0.017\end{array}$ & -0.152 & 0.017 \\
\hline $\begin{array}{l}\text { AHI-REM, } \\
1 \text { event/hour of sleep }\end{array}$ & $\begin{array}{c}0.002 \pm \\
0.007\end{array}$ & 0.015 & 0.798 & $\begin{array}{c}-0.005 \pm \\
0.006\end{array}$ & -0.038 & 0.458 & $\begin{array}{l}-0.003 \pm \\
0.006\end{array}$ & -0.028 & 0.600 \\
\hline Gender, male & $\begin{array}{c}0.116 \pm \\
0.108\end{array}$ & 0.066 & 0.285 & $\begin{array}{c}-0.089 \pm \\
0.101\end{array}$ & -0.049 & 0.382 & $\begin{array}{c}0.036 \pm \\
0.094\end{array}$ & 0.022 & 0.702 \\
\hline Age, 1 year & $\begin{array}{c}-0.012 \pm \\
0.004\end{array}$ & -0.175 & 0.003 & $\begin{array}{c}0.027 \pm \\
0.004\end{array}$ & 0.380 & 0.000 & $\begin{array}{c}0.021 \pm \\
0.003\end{array}$ & 0.338 & 0.000 \\
\hline $\mathrm{BMl}, 1 \mathrm{~kg} / \mathrm{m}^{2}$ & $\begin{array}{c}0.020 \pm \\
0.015\end{array}$ & 0.086 & 0.181 & $\begin{array}{c}-0.019 \pm \\
0.014\end{array}$ & -0.076 & 0.189 & $\begin{array}{c}-0.036 \pm \\
0.013\end{array}$ & -0.164 & 0.007 \\
\hline
\end{tabular}

AHI: apnea-hyponea index; AHI-N1: apnea-hyponea index during stage 1 sleep; AHI-N2: apnea-hyponea index during stage 2 sleep; AHI-REM: apnea-hyponea index during rapid eye movement sleep; BMI: body mass index; B: angular coeffi-

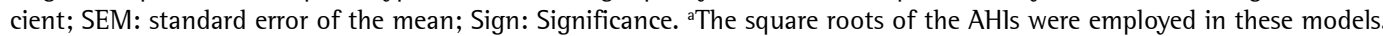


Table 5 - Percentage of diagnoses obtained when using different dimensions of sleepiness.

\begin{tabular}{lcccc}
\hline \multicolumn{1}{c}{ Dimension } & OSAHS & UARS & SDB & Normal \\
\hline Epworth sleepiness scale & 16 & 18 & 26 & 40 \\
Latency to stage 2 & 10 & 8 & 32 & 50 \\
Sleep efficiency & 24 & 25 & 18 & 33 \\
Years of sleepiness & 23 & 22 & 23 & 32 \\
Sleepiness as the chief complaint (yes/no) & 9 & 8 & 33 & 50 \\
Presence of comorbidities (yes/no) & 10 & 11 & 32 & 47 \\
Timing of sleepiness (morning/afternoon) & 38 & 43 & 4 & 15 \\
Sleepiness while driving (yes/no) & 14 & 18 & 29 & 39 \\
Sleepiness while working (yes/no) & 17 & 16 & 26 & 41 \\
lnsomnia as the chief complaint (yes/no) & 14 & 30 & 29 & 27 \\
\hline OSAHS: obstur
\end{tabular}

OSAHS: obstructive sleep apnea-hypopnea syndrome; UARS: upper airway resistance syndrome; and SDB: sleep-disordered breathing.

sleepiness) were excluded due to reasons that will be discussed below. The intraclass correlation coefficient was $0.254(p<0.001)$ and the standardized Cronbach's alpha was 0.715 , indicating that the seven remaining dimensions are measures of sleepiness.

A factor analysis was performed using the seven sleepiness dimensions included in the reliability analysis. Of the factors derived from those seven variables, three presented an eigenvalue $>1$ and were therefore included in the analyses. Those three factors explained $72 \%$ of the total sample variance. Correlations of the seven variables with each factor are shown in Table 3. The Kaiser-Meyer-Olkin statistic was 0.68 , indicating good sampling adequacy. The first factor (QUESTIONNAIRE) correlated with the ESS dimensions "sleepiness at the wheel", and "sleepiness at work", with a Cronbach's alpha of 0.7. The second factor (POLYSOMNOGRAPHY) correlated with the polysomnographic variables: "sleep urgency" (the inverse of latency to stage 2) and "sleep efficiency", with a Cronbach's alpha of 0.68. The third factor (COMPLAINTS) correlated with the clinical interview variables "sleepiness as the chief complaint" and "insomnia as the chief complaint", with a Cronbach's alpha of 0.55.

The results of the multivariate analysis are shown in Table 4. After adjusting for gender, age and BMI, we found that the AHI-N1 correlated significantly with the factor POLYSOMNOGRAPHY ( $\beta=-0.173, p=0.003)$, the AHI-N2 correlated significantly with the factor COMPLAINTS ( $\beta=-0.152, p=0.017)$, and the AHI-REM did not correlate with any factor.

We used $2 \times 2$ tables in order to determine the impact that changing the sleepiness dimension has on the diagnosis of OSAHS. Insomnia was identified based on a diagnostic criterion similar to that used in the identification of sleepiness. Morning/afternoon sleepiness was considered as positive for a diagnosis of OSAHS when it was more prominent in the morning. When utilizing the four parametric variables, sleep efficiency $>85 \%$, latency to stage $2<10 \mathrm{~min}$, ESS score $>10$ and years since EDS onset $>4$ were considered indicative of sleepiness. Using the ten dimensions of sleepiness and the AHls to define the four possible diagnoses (Table 5), we found that the percentage of cases with OSAHS ranged from $9 \%$ to $38 \%$, compared with $8 \%$ to $43 \%$ for UARS, $4 \%$ to $33 \%$ for SDB and $15 \%$ to $50 \%$ for normal.

\section{Discussion}

The present study was conducted in order to determine whether a different approach would confirm the Kass et al. finding of an association between objective sleepiness and SDB during REM sleep. ${ }^{(8)}$ We hypothesized that subjective scales of sleepiness could provide new insights into this issue. However, our findings do not support the proposition that fragmentation of REM sleep might be more important than is overall sleep fragmentation in causing EDS, perhaps because our sample was considerably larger than that evaluated in the Kass et al. study $(\mathrm{n}=331$ vs. $\mathrm{n}=34){ }^{(8)}$

The retrospective nature of the study could be considered a limitation, as could the fact that we employed indices of somnolence that are both subjective and speculative. Nevertheless, our findings are in agreement with those of two other large-scale studies, ${ }^{(9,10)}$ in which 
the AHI-REM was not identified as a cause of MSLT-proven EDS. One of those studies involved 342 patients with an AHI-TST $<10$ and showed that the AHI-TST is significantly correlated with MSLT, whereas the AHI-REM is not. ${ }^{(9)}$ This is similar to our finding that five of the ten dimensions of sleepiness correlated significantly with the AHI-N1, AHI-N2 and AHI-TST, although not with the AHI-REM. The AHI in REM and NREM sleep correlated differently because we selected patients with an AHI-TST $<10$ in order to facilitate the comparison between our results and those of Kass et al. Most studies investigating SDB in REM vs. NREM sleep have utilized the full range of AHls and are, therefore, non-comparable with the present study that follows the unique methodology utilized by Kass et al. ${ }^{(8)}$

Our data reject the Kass et al. hypothesis that REM-specific SDB is an early or prodromal phase of OSAHS. In view of the numerous reports that the AHI-REM does not correlate with objective or subjective sleepiness, the possibility that SDB in REM sleep does not represent a disease state has to be considered. Various physiological instabilities are germane to the REM state. Breathing can be disordered in REM sleep as a reflex of this overall instability rather than of specific respiratory control abnormalities. This could explain why the AHI-REM is the only stage-specific $\mathrm{AHI}$ that did not correlate with any of the dimensions of sleepiness evaluated in the present study. However, the fact that the AHI-NREM correlated significantly with sleepiness in this initial stage of SDB indicates that EDS is one of the early manifestations of SDB..$^{(12)}$

Our results show that some putative dimensions of sleepiness correlate with some stage-specific AHls, although only a few of those correlations remained after being adjusted for gender, age, and BMl in the multivariate analysis. It is of note that we found no gender effect in sleepiness dimensions; nor did we find SDB clustering during REM sleep in women. Interestingly, in the present analysis, the only $\mathrm{AHI}$ that was found to be similar in men and women is AHI-REM (Table 1). All these findings are in contrast with those of previous reports. ${ }^{(17,29)}$ This discrepancy can be due to ample dissimilarities between the study samples in terms of the male/ female ratio, age and BMI. In our study, approximately $7 \%$ of the patients were diagnosed with depression, which was more prevalent in the women. Although depression is a known confounding factor, it was not found to correlate with any of the sleepiness dimensions or with any of the AHls in the univariate or the multivariate analysis.

In the most cited study in the sleep literature, ${ }^{(30)} 9 \%$ of females and 24\% of males had a respiratory disturbance index $>5$. Interestingly, only $2 \%$ of the women and $4 \%$ of the men reported EDS, a prevalence that is lower than that reported in most of the literature. This discrepancy is likely due to the non-validated questions used by the authors to identify sleepiness. It would be interesting to investigate population data using different dimensions of sleepiness. In the present study, the percentage of patients diagnosed with OSAHS ranged from $9 \%$ to $38 \%$ when different indicators of EDS were used. One point to be considered, however, is that the Portuguese-language version of the ESS has not been formally validated. The use of a translation might have affected the psychometric properties of the scale and the use of the score of 10 as normal limit might therefore have been inappropriate. Despite this limitation, the ESS score has been shown to correlate significantly with the AHI in NREM sleep and in TST.

Our results provide additional insight into the relationship between sleepiness and the $\mathrm{AHI}$ in different sleep stages, suggesting that the AHI-REM is not associated with polysomnographic or patient-reported dimensions of sleepiness.

\section{References}

1. Parati G, Lombardi C, Narkiewicz K. Sleep apnea: epidemiology, pathophysiology, and relation to cardiovascular risk. Am J Physiol Regul Integr Comp Physiol. 2007;293(4):R1671-83.

2. Germanowicz D, Lumertz MS, Martinez D, Margarites AF. Sleep disordered breathing concomitant with fibromyalgia syndrome. J Bras Pneumol. 2006;32(4):333-8.

3. George CF. Sleep apnea, alertness, and motor vehicle crashes. Am J Respir Crit Care Med. 2007;176(10):954-6.

4. Viegas CA, de Oliveira HW. Prevalence of risk factors for obstructive sleep apnea syndrome in interstate bus drivers. J Bras Pneumol. 2006;32(2):144-9.

5. Martinez D. Obstructive sleep apnea: a contagious disease? J Bras Pneumol. 2006;32(2):ix-x.

6. Martins AB, Tufik S, Moura SM. Physiopathology of obstructive sleep apnea-hypopnea syndrome. J Bras Pneumol. 2007;33(1):93-100.

7. Weaver EM, Kapur V, Yueh B. Polysomnography vs selfreported measures in patients with sleep apnea. Arch Otolaryngol Head Neck Surg. 2004;130(4):453-8. 
8. Kass JE, Akers SM, Bartter TC, Pratter MR. Rapideye-movement-specific sleep-disordered breathing: a possible cause of excessive daytime sleepiness. Am J Respir Crit Care Med. 1996;154(1):167-9.

9. Chervin RD, Aldrich MS. The relation between multiple sleep latency test findings and the frequency of apneic events in REM and non-REM sleep. Chest. 1998;113(4):980-4.

10. Punjabi NM, Bandeen-Roche K, Marx JJ, Neubauer DN, Smith PL, Schwartz AR. The association between daytime sleepiness and sleep-disordered breathing in NREM and REM sleep. Sleep. 2002;25(3):307-14.

11. Bonnet MH. ACNS clinical controversy: MSLT and MWT have limited clinical utility. J Clin Neurophysiol. 2006;23(1):50-8.

12. Guilleminault C, Stoohs R, Clerk A, Cetel M, Maistros P. A cause of excessive daytime sleepiness. The upper airway resistance syndrome. Chest. 1993;104(3):781-7.

13. Punjabi NM, O'hearn DJ, Neubauer DN, Nieto FJ, Schwartz AR, Smith PL, et al. Modeling hypersomnolence in sleep-disordered breathing. A novel approach using survival analysis. Am J Respir Crit Care Med. 1999;159(6):1703-9.

14. Gottlieb DJ, Whitney CW, Bonekat WH, lber C, James GD, Lebowitz M, et al. Relation of sleepiness to respiratory disturbance index: the Sleep Heart Health Study. Am J Respir Crit Care Med. 1999;159(2):502-7.

15. Johns MW. A new method for measuring daytime sleepiness: the Epworth sleepiness scale. Sleep. 1991;14(6):540-5.

16. Johns M. Rethinking the assessment of sleepiness. Sleep Med Rev. 1998;2(1):3-15.

17. Kim H, Young T. Subjective daytime sleepiness: dimensions and correlates in the general population. Sleep. 2005;28(5):625-34.

18. Sleep-related breathing disorders in adults: recommendations for syndrome definition and measurement techniques in clinical research. The Report of an American Academy of Sleep Medicine Task Force. Sleep. 1999;22(5):667-89.

19. American Academy of Sleep Medicine. The international classification of sleep disorders diagnostic and coding manual. Westchester: American Academy of Sleep Medicine; 2005.

20. Braga CW, Martinez D, Wofchuk S, Portela LV, Souza D0. S100B and NSE serum levels in obstructive sleep apnea syndrome. Sleep Med. 2006;7(5):431-5.

21. Bittencourt LR, coordinator. Diagnóstico e tratamento da síndrome da apnéia obstrutiva do sono (SAOS) - Guia prático. São Paulo: LMP; 2008.

22. Iber C, Ancoli-lsrael S, Cheeson Jr A, Quan SF. The AASM Manual for the Scoring of Sleep and Associated Events: Rules, Terminology and Technical Specification. Westchester: American Academy of Sleep Medicine; 2007.

23. Chervin RD, Kraemer HC, Guilleminault C. Correlates of sleep latency on the multiple sleep latency test in a clinical population. Electroencephalogr Clin Neurophysiol. 1995;95(3):147-53.

24. Bixler E0, Vgontzas AN, Lin HM, Calhoun SL, VelaBueno A, Kales A. Excessive daytime sleepiness in a general population sample: the role of sleep apnea, age, obesity, diabetes, and depression. J Clin Endocrinol Metab. 2005;90(8):4510-5.

25. Chellappa SL, Araújo JF. Excessive daytime sleepiness in patients with depressive disorder. Rev Bras Psiquiatr. 2006;28(2):126-9.

26. Kjelsberg FN, Ruud EA, Stavem K. Predictors of symptoms of anxiety and depression in obstructive sleep apnea. Sleep Med. 2005;6(4):341-6.

27. Sanford SD, Lichstein KL, Durrence HH, Riedel BW, Taylor DJ, Bush AJ. The influence of age, gender, ethnicity, and insomnia on Epworth sleepiness scores: a normative US population. Sleep Med. 2006;7(4):319-26.

28. Johns MW. Sleepiness in different situations measured by the Epworth Sleepiness Scale. Sleep. 1994;17(8):703-10.

29. O'Connor C, Thornley KS, Hanly PJ. Gender differences in the polysomnographic features of obstructive sleep apnea. Am J Respir Crit Care Med. 2000;161(5):1465-72.

30. Young T, Palta M, Dempsey J, Skatrud J, Weber $\mathrm{S}$, Badr S. The occurrence of sleep-disordered breathing among middle-aged adults. $\mathrm{N}$ Engl J Med. 1993;328(17):1230-5.

\section{About the authors}

\section{Denis Martinez}

Associate Professor in the Department of Internal Medicine. Universidade Federal do Rio Grande do Sul - UFRGS, Federal University of Rio Grande do Sul - Porto Alegre, Brazil.

\section{Magali Santos Lumertz}

Resident in Pediatrics. Hospital Santo Antonio, Porto Alegre, Brazil.

Maria do Carmo Sfreddo Lenz

Pulmonologist. Sleep Disorder Clinic, Porto Alegre, Brazil. 